\title{
“I THINK HAVING ASPERGER'S HELPED ME WITH MY TRANSGENDER IDENTITY": THE LIVED EXPERIENCES OF YOUTH WITH GENDER DIVERSE IDENTITIES AND AUTISM SPECTRUM DISORDERS
}

\author{
Wallace Wong ${ }^{1}$, Jaime Semchuk ${ }^{2}, \&$ Veronique Nguy $^{2}$ \\ ${ }^{1}$ Diversity Emotional Wellness Centre (Canada) \\ ${ }^{2}$ University of British Columbia (Canada)
}

\begin{abstract}
With a growing body of research suggesting the co-occurrence of autism spectrum disorders (ASD) and gender variance $(\mathrm{GV})$, only a handful of published studies have investigated the perspectives and experiences of GV youth with ASD. Current clinical care guidelines for this population have generally been obtained through expert knowledge and fail to consider the contribution and perspectives of key stakeholders with an insider perspective such as youth and their caregivers. As such, a semi-structured focus-group and interview were conducted to explore the experiences and perspectives of four GV youth with ASD. Interviews were transcribed and analyzed for themes. The key themes identified were: 1) a clear understanding of their gender identity and related needs 2) significant perceived stigma related to their ASD diagnosis, 3) recognition of how ASD identity and gender identity intersect and impact one another, 4) complexities of medical systems can be challenging to navigate for youth with ASD, so a comprehensive team approach to services is important. This study seeks to increase our understanding of this population and contribute to improving the quality of clinical services for this transgender youth with ASD.
\end{abstract}

Keywords: Gender variance, autism spectrum disorders, gender identity, access to services, youth perspectives.

\section{Introduction}

Accumulating research indicates that children and adolescents with co-occurring autism spectrum disorders (ASD) and gender variance $(\mathrm{GV})$ are identified at higher rates than would be expected by chance (de Vries, Noens, Cohen-Kettenis, van Berckelaer-Onnes, \& Dorelihers, 2010; Skagerberg, Di Ceglie, \& Carmichael, 2015; Janssen, Huang, \& Duncan, 2016; Shumer, Reisner, Edwards-Leeper, \& Tishelman, 2016; van der Miesen, Hurley, Bal, \& de Vries, 2018). Current available studies looking at rates of clinical ASD diagnosis in gender-referred youth suggest a co-occurence rate of 6.3 to $13.3 \%$ (de Vries et al., 2010; Holt, Skagerberg, \& Dunsford, 2016; Nahata, Quinn, Caltabellotta, \& Tischelman, 2017; Shumer et al., 2016).

The clinical assessment and treatment of gender-variant children and youth with autism can prove complex, due to the developmental aspects of ASD (de Vries et al., 2010; Strang, et al., 2018). Recently, clinical care guidelines for this population were developed by obtaining consensus among professionals with expertise in the field (Strang, et al., 2018). However, these guidelines lacked the contribution of the expertise afforded by those with lived experience. To our knowledge, there are only a handful of studies to date that addresses the clinical needs, perspectives, and experiences of gender variant-youth with autism (Strang et al., 2018; Strang et al., 2018). In order to better understand and provide effective clinical services for this population, it is important to learn about the perspectives of key stakeholders with an insider perspective (Strang et al., 2018; Strang et al., 2018). The present study seeks to contribute to this body of research by asking the following question: What are the experiences of GV youth with ASD related to understanding their identities and accessing clinical services? 


\section{Participants and methods}

Table 1. Participant Demographics.

$\begin{array}{cccc}\begin{array}{c}\text { Participan } \\ \text { t }\end{array} & \text { Age } & \begin{array}{c}\text { Gender } \\ \text { Identity }\end{array} & \text { Diagnosis } \\ \begin{array}{c}\text { Participant } \\ 1\end{array} & 13 & \begin{array}{c}\text { Transgender } \\ \text { Female }\end{array} & \begin{array}{c}\text { Pervasive Developmental Disorder-Not } \\ \text { Otherwise Specified }\end{array} \\ \begin{array}{c}\text { Participant } \\ 2\end{array} & 16 & \begin{array}{c}\text { Transgender } \\ \text { Male }\end{array} & \text { Autism Spectrum Disorder } \\ \begin{array}{c}\text { Participant } \\ 3\end{array} & 17 & \begin{array}{c}\text { Transgender } \\ \text { Female }\end{array} & \text { Asperger's Syndrome } \\ \text { Participant } & 19 & \text { Transgender } & \\ 4 & & \text { Male } & \text { Asperger's Syndrome }\end{array}$

Four participants were recruited from a community-based mental health services clinic in the Lower Mainland of British Columbia, Canada. All participants identified as gender variant and had a diagnosed Autism Spectrum Disorder. Informed consent was obtained from each participant and their legal guardian to take part in the study. This study was conducted in March 2018 using a qualitative semi-structured interview format. An initial focus group was conducted with three of the participants, and a separate interview was conducted individually with another youth who also wished to participate, but was unavailable during the time of the initial focus group. All interviews were audio recorded, transcribed, and analyzed for emergent themes using qualitative thematic analysis (Braun \& Clarke, 2006).

\section{Results}

Figure 1. Organization of Themes.

\begin{tabular}{|c|c|c|c|c|}
\hline Broad Themes & $\begin{array}{c}\text { Understanding Gender } \\
\text { Identity (GI) }\end{array}$ & $\begin{array}{c}\text { Understanding } \\
\text { Autism Spectrum } \\
\text { Disorders (ASD) }\end{array}$ & $\begin{array}{c}\text { Intersection of } \\
\text { ASD and GI }\end{array}$ & $\begin{array}{c}\text { Navigating } \\
\text { Systems }\end{array}$ \\
\hline Sub-themes & Self-Awareness & $\begin{array}{c}\text { ASD Stigma and } \\
\text { Stereotypes }\end{array}$ & $\begin{array}{c}\text { Invalidation of GI } \\
\text { due to ASD } \\
\text { Diagnosis }\end{array}$ & $\begin{array}{c}\text { Additional } \\
\text { Challenges }\end{array}$ \\
\cline { 2 - 5 } & $\begin{array}{c}\text { Challenges Explaining } \\
\text { GI to Others }\end{array}$ & $\begin{array}{c}\text { Unlikely to Disclose } \\
\text { ASD Diagnosis to } \\
\text { Others }\end{array}$ & $\begin{array}{c}\text { Benefits of ASD } \\
\text { and Transgender } \\
\text { Identity }\end{array}$ & Helpful Supports \\
\hline
\end{tabular}

\subsection{Understanding gender identity}

Participants discussed their self-awareness of their gender identity and indicated their transgender identity was something that felt innate to them. For instance, one participant stated, "It is something I'm born with. It wasn't something I chose to be...I can't force myself not to be transgender. Either you are or you're not. That's the best I can describe it." Participants also identified challenges describing their gender identity to others. The fluid nature of gender made it difficult for participants to communicate with others about their transgender identity. As one participant described, "Because I take things so literal - gender can sometimes be very fluid and vague, the definition, so it's kind of hard to tell people how you feel."

\subsection{Understanding autism spectrum disorder}

During interviews, participants highlighted the perceived stigma and stereotypes others attribute to ASD. One participant shared, "People think I'm just great with anything with science and math. And anything to do with socializing, I'm bad at. Like two extremes." Relatedly, another participant stated, "Living with autism, it sucks. To be honest, just because of the fact you're different from other people, you 
receive doubts from other people because they think you're not mentally capable of comprehending things." Due to perceived negative stereotypes, participants reported they were unlikely to disclose their ASD diagnosis to others. According to one participant, "No, I just mostly ignore it. I don't talk about being autistic at all."

\subsection{Intersection of ASD and gender identity}

Participants reported experiencing invalidation of their transgender identity due to their ASD diagnosis, including having others disregard their gender identity, or expressing disbelief. A participant shared, "Because people always assume because someone has a disorder like autism or something, they don't understand anything...just people trying to tell you how you are feeling, just assuming." Participants also identified the benefits of having both ASD and a transgender identity. For instance, participants perceived that living in their affirmed gender helped facilitate an increase in social interactions, addressing a deficit associated with ASD. Further, another participant indicated that symptoms of ASD helped them when facing mental health challenges related to their transgender identity, as illustrated in the following excerpt, "I think having Asperger's helped me with my transgender identity, especially during times you get depressed...I know having Asperger's made me stick with my schedule...it helped keep me going."

\subsection{Navigating systems}

Finally, participants identified additional challenges navigating systems when accessing clinical services related to their ASD and transgender identity. Specifically, communicating with professionals to access services, relying on others for help, and misunderstanding information all posed challenges for participants. A participant shared, "To be transgender you have to make a lot of phone calls with people you've never heard of... and having autism can be difficult. You have to rely on other people to help." However, participants also experienced helpful supports when accessing services. These supports included having parents who validate their child's gender identity and are willing to attend appointments with their children. One participant highlighted, "My mom was always with me at appointments because sometimes I wouldn't understand the doctor. She's known me a lot longer and she would know how to explain it to me." Other helpful supports included accessing services from professionals who were willing to simplify information and provide extra time during appointments. A participant suggested, "Definitely try to outline steps more clearly...try talking more slowly."

\section{Discussion}

In this study, all participants were aware of their gender identity, but found it challenging to explain their identity to others. Youth with ASD commonly experience challenges with social communication (American Psychiatric Association, 2013). As a result, some caregivers or professionals may underestimate their ability to understand their gender identity. Additionally, others may question the authenticity of a transgender identity for a youth with ASD. Due to perceived negative stereotypes, some trans-youth with ASD reported that they were unlikely to disclose their ASD diagnosis to others, fearing that other people may not believe or challenge the authenticity of their gender identity. However, when a transgender youth with ASD chooses to withhold information, at times, it may limit services and impede the opportunity for them to receive specialized services and appropriate care. Finally, participants found it challenging to navigate our medical system and access related clinical services. They found comfort in having a supportive adult by their side during appointments. Medical and mental health professionals may also lack training and understanding of how to work with this specific population, which has the potential to affect the quality of services.

\subsection{Limitations}

In this study, participants consisted of four transgender youth with ASD accessing publicly funded mental health and medical services. They all had a basic level of family support and were under the age of twenty. Thus, the generalizability of our results to other transgender youth who are not accessing healthcare services, supported by family or older than nineteen years old is unknown. The sample size of this study is relatively small. A larger sample size may have produced different results. Lastly, having the psychologist as a focus group facilitator may have biased the responses of some participants who were also under his care.

\subsection{Conclusion}

In our study, participants had a clear understanding of their gender identity and related needs. Participants' greatest challenges were caregivers', professionals', and the public's' lack of understanding of their intersecting identities related to their transgender identity and ASD diagnosis, as well as difficulties 
associated with navigating and accessing related services. There is very limited research focused on this population and professionals may lack appropriate training and guidelines when providing services. Although this study has its limitations, we believe that the results from this study can inform healthcare and clinical professionals of specific considerations when providing services for transgender youth with ASD. For a transgender youth diagnosed with ASD, learning how to navigate the medical and mental health systems is not easy. For this reason, increasing public awareness and providing a wraparound, step-by-step approach to services may prove helpful for this population. The findings from this study may provide some direction for future research.

\section{References}

American Psychiatric Association, American Psychiatric Association. DSM-5 Task Force, \& PsychiatryOnline

Premium Package. (2013). Diagnostic and statistical manual of mental disorders: DSM-5 (5th ed.). Washington, D.C: American Psychiatric Association.

Braun, V., \& Clarke, V. (2006). Using thematic analysis in psychology. Qualitative research in psychology, $3(2), 77-101$.

De Vries, A. L., Noens, I. L., Cohen-Kettenis, P. T., van Berckelaer-Onnes, I. A., \& Doreleijers, T. A. (2010).

Autism spectrum disorders in gender dysphoric children and adolescents. Journal of autism and developmental disorders, 40(8), 930-936.

Holt, V., Skagerberg, E., \& Dunsford, M. (2016). Young people with features of gender dysphoria: Demographics and associated difficulties. Clinical Child Psychology and Psychiatry, 21(1), 108-118.

Janssen, A., Huang, H., \& Duncan, C. (2016). Gender variance among youth with autism spectrum disorders: A retrospective chart review. Transgender Health, 1(1), 63-68.

Nahata, L., Quinn, G. P., Caltabellotta, N. M., \& Tischelman, A. C. (2017). Mental health concerns and insurance denials among transgender adolescents. LGBT Health, 4(3), 188- 193

Shumer, D. E., Reisner, S. L., Edwards-Leeper, L., \& Tishelman, A. (2016). Evaluation of Asperger syndrome in youth presenting to a gender dysphoria clinic. LGBT Health, 3(5), 387-390.

Skagerberg, E., Di Ceglie, D., \& Carmichael, P. (2015). Brief report: Autistic features in children and adolescents with gender dysphoria. Journal of autism and developmental disorders, 45(8), 2628-2632.

Strang, J. F., Meagher, H., Kenworthy, L., de Vries, A. L. C., Menvielle, E., Leibowitz, S., ... Anthony, L. G. (2018). Initial clinical guidelines for co-occurring autism spectrum disorder and gender dysphoria or incongruence in adolescents. Journal of Clinical Child and Adolescent Psychology, 47(1), $105-115$.

Strang, J. F., Powers, M. D., Knauss, M., Sibarium, E., Leibowitz, S. F., Kenworthy, L., ... \& Pervez, N. (2018). "They thought it was an obsession": Trajectories and Perspectives of Autistic Transgender and Gender-Diverse Adolescents. Journal of autism and developmental disorders, 48(12), 4039-4055.

van der Miesen, A. I., Hurley, H., Bal, A. M., \& de Vries, A. L. (2018). Prevalence of the Wish to be of the Opposite Gender in Adolescents and Adults with Autism Spectrum Disorder. Archives of sexual behavior, 47(8), 2307-2317. 